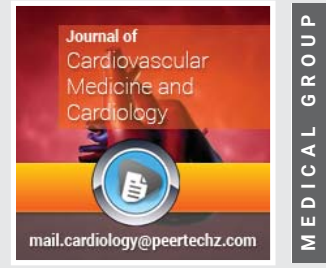

\title{
A combination of depression and decreased physical function further worsens the prognosis of patients with chronic cardiovascular disease
}

\author{
Kenya Osada', Minako Yamaoka-Tojo ${ }^{2 *}$, Shinichi Obara ${ }^{3}$, \\ Hidenori Kariya ${ }^{4}$, Yohei Kato ${ }^{1}$, Akinori Yuyama ${ }^{1}$, Kentaro \\ Kamiya $^{2}$, Atsuhiko Matsunaga ${ }^{2}$ and Junya $\mathbf{A k o}^{5}$ \\ ${ }^{1}$ Kitasato University Graduate School of Medical Sciences, Sagamihara, Japan \\ ${ }^{2}$ Department of Rehabilitation, Kitasato University School of Allied Health Sciences, Sagamihara, \\ Japan \\ ${ }^{3}$ Department of Rehabilitation, Kitasato University East Hospital, Sagamihara, Japan \\ ${ }^{4}$ Department of Rehabilitation, Kitasato University Hospital, Sagamihara, Japan \\ ${ }^{5}$ Department of Cardiovascular Medicine, Kitasato University School of Medicine, Sagamihara, Japan
}

Received: 16 April, 2020

Accepted: 20 April, 2020

Published: 21 April, 2020

*Corresponding author: Minako Yamaoka-Tojo, MD, Postal address: 1-15-1 Kitasato, Minami-ku, Sagamihara 252-0373, Japan,

E-mail:myamaoka@med.kitasato-u.ac.jp

ORCID: https://orcid.org/0000-0003-3890-3777

Keywords: Hospital anxiety and depression scale; Muscle strength; Gait speed; Exercise tolerance; Allcause mortality; Readmission due to heart failures

https://www.peertechz.com

Check for updates

\begin{abstract}
Background: Patients with Cardiovascular Disease (CVD) have high rates of depression and decreased physical function. In addition, the physical function has been reported to decline in patients with depression. However, there is no clear relationship between depression and physical function in patients with CVD. Moreover, the effects of the combination of depression and decreased physical function on prognosis are unclear. This study was performed to clarify the relationship between depression and physical function, in the prognosis of patients with CVD.
\end{abstract}

Methods: The study population consisted of 472 patients with chronic CVD. We investigated depression by Hospital Anxiety and Depression Scale (HADS), and physical function by grip strength, quadriceps isometric strength, gait speed, and 6-Minute Walking Distance (6MWD). The prognosis was investigated in patients divided into three groups according to HADS and physical function.

Results: Among the 472 patients, 109 (23.1\%) had depressive tendency according to HADS. An analysis of covariance, all physical function showed significantly low values in combination with depressive tendency. Kaplan-Meier analysis followed by Bonferroni's multiple comparison test revealed that the incidences of all-cause mortality and readmission due to heart failure were significantly higher in patients with depressive and decreased $6 \mathrm{MWD}$ than in those with only one feature. In cox proportional hazards analysis, only the combination of depressive tendency and decreased 6MWD further increased the risk of all-cause mortality and readmission due to heart failure. CVD.

Conclusions: Depressive tendency is associated with decreased physical function, and their combination is associated with poor prognosis in patients with chronic

\section{Introduction}

The aging of the population in Japan is accompanied by increases in the number of elderly patients with heart disease.
It has been reported that the rate of depression is high in patients with Cardiovascular Disease (CVD) [1-3] for several reasons. However, the treatment of depression is difficult in patients with CVD. This is because cardiologists who are 
not specialists in depression oversee the treatment of these patients, so depression may be overlooked or appropriate treatment may not be provided. The American College of Cardiology has recommended regular screening for depression in patients with CVD since 2008 [4]. According to the World Health Organization, the main causes of disease burden related to morbidity and mortality are expected to be unipolar depressive disorder followed by ischemic heart disease by 2030 [5]. Therefore, it is important to prevent and treat depression and cardiovascular disease. Depressed CVD patients have been reported to have increased cardiovascular events and mortality [6-8]. Besides, increasing the severity of symptoms of depression has been reported to further increase the risk of cardiovascular events. [9] Elderly community-dwelling people with depression have also been reported to have increased cardiovascular events and mortality [10-12] and they have been reported to be associated with decreased physical function [13] and physical activity [14]. The decreased physical function has been reported to be an independent determinant of prognosis in patients with CVD and community-dwelling elderly people [15-17]. However, there have been few investigations regarding the relationship between depression and physical function in patients with CVD, and few studies of the effects of the combination of depression and decreased physical function on prognosis.

Clarification of the relationship between depression and physical function in patients with CVD will be useful for screening patients who are prone to a decrease in physical function, leading to improved prognosis and reduction of medical costs. This study was performed to clarify the relationship between depression and physical function in patients with CVD, and the effects of the combination of depression and decreased physical function on prognosis.

\section{Materials \& methods}

\section{Study population}

The study population consisted of 472 chronic CVD patients over the age of 40 whose HADS $[18,19]$ and physical function could be measured simultaneously during outpatient visits between April 2011 and December 2018. The definition of patients with chronic cardiovascular disease was 6 months or more after the diagnosis of heart disease, and patients with any heart disease such as ischemic heart disease and heart valve disease who have prescribed an outpatient heart disease secondary prevention program. This was a retrospective study in a cohort with prescriptions for cardiac rehabilitation at the Kitasato University Cardiovascular Prevention Center. Those who re-hospitalized for heart failure within six months from the measurement, those who had a diagnosis of depression, were excluded. This study was performed by the Declaration of Helsinki and approved by the Ethics Committee of Kitasato University Hospital.

\section{Data collection}

Data on all variables were collected from the patients' electronic medical records. We recorded the clinical details for patients, including diagnosis, comorbidities, echocardiography, blood biochemical test results, medication use, and demographic characteristics. The Body Mass Index (BMI) was calculated as body weight $(\mathrm{kg})$ divided by height $(\mathrm{m})$ squared. The estimated Glomerular Filtration rate (eGFR) was defined according to the formula of the Japanese Society of Nephrology [20]. B-type Natriuretic Peptide (BNP) concentration was determined using a commercial immunoradiometric assay (Shionogi, Osaka, Japan). Simpson's method was used to estimate the Left Ventricular Ejection Fraction (LVEF) from 2D echocardiograms.

\section{Depressive tendency index}

HADS was used as an indicator of depressive tendency $[18,19]$. HADS is a self-administered scale developed to assess depression and anxiety in outpatients, which consists of seven items related to depression and seven items related to anxiety. In this study, we investigated seven items related to depression. Each item consists of 4 levels, $0-3$ points, suggesting that a higher score is associated with stronger depressive tendencies.

\section{Physical function measurement}

Grip strength, Quadriceps Isometric Strength (QIS), 10-m usual gait speed, and 6-Minute Walking Distance (6MWD) were measured as parameters of physical function. Grip strength was measured using a grip strength meter (Handgrip Meter 6103, Tanita, Tokyo, Japan). The upper limb was measured at the shoulder position in the middle position of the shoulder joint, with the elbow joint at $90^{\circ}$ flexion, and the middle position of the forearm. The measurement was performed with isometric contraction for $3 \mathrm{~s}$ each on the left and right sides, and the average of the left and right maximum values was used in the analysis. The QIS was measured using a handheld dynamometer ( $\mu$-Tas; ANIMA, Tokyo, Japan). The patient was seated so that the hip and knee joints were at $90^{\circ}$ with the dynamometer fixed to the front of the lower leg so that the lower end of the pressure sensor was two finger-widths above the lateral malleolus. The measurement of QIS was performed twice in $5 \mathrm{~s}$, and the value obtained by dividing the average of the left and right maximum values by body weight (\% BW) was used in the analysis. Gait speed was determined as the sped of walking in a straight line over a distance of $16 \mathrm{~m}$ including a 6-m runway. The time required to cover a distance of $10 \mathrm{~m}$ at usual gait was measured with a stopwatch, and the usual gait speed $(\mathrm{m} / \mathrm{s})$ was calculated. The measurement was performed once, and the value was used in the analysis. 6MWD was measured according to the report of the American Thoracic Society [21]. Briefly, the subject walked as far as possible in 6 minutes, and the distance $(\mathrm{m})$ was used in the analysis.

\section{Definition of decreased physical function}

The cut-off values for decreased physical function in this study were based on previous reports. The values for grip strength were $<26 \mathrm{~kg}$ for males and $<18 \mathrm{~kg}$ for females [22], QIS was 40\% BW [23], gait speed over $10 \mathrm{~m}$ was $<1.0 \mathrm{~m} / \mathrm{s}$ [24],

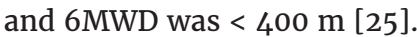

\section{Outcome measure}

The primary outcome measures of this study were all- 
cause mortality and readmission due to heart failure. The time to the events was calculated as the number of days from the date of HADS and physical function measurement to the date of the event.

\section{Statistical analysis}

Regarding previous research, the HADS cut-off value was set to 8 points; subjects with $\geq 8$ points were classified as the depressive tendency group, and those with $\leq 7$ points were classified as the non-depressive tendency group in this study [26]. We compared clinical background factors according to the presence of depressive tendencies. For continuous variables, the Mann-Whitney U test was used. For nominal measures, the $\chi_{2}$ test or Fisher's exact test was used. The results are shown as the median (interquartile range) for non-normally distributed indices. To examine the relationship between depressive tendency and physical function, we conducted multiple regression analysis with the dependent variable as the physical function index. In Model 1, independent variables were age, gender, BMI, and HADS. Model 2 added hemoglobin A1c (HbA1c), Albumin (Alb), eGFR, C-Reactive Protein (CRP), BNP, LVEF, and the presence or absence of chronic heart failure to Model 1. Model 3 added the presence or absence of hypertension, dyslipidemia, diabetes, and smoking, which are coronary risk factors, to Model 2. We also performed covariance analysis with age, gender, BMI, HbA1c, Alb, eGFR, CRP, BNP, LVEF and the presence or absence of chronic heart failure as covariates, and compared the physical function according to the presence or absence of depressive tendency. The associations between depressive tendency, physical function, and prognosis were classified into three groups: Non-D and High-P group, with neither depressive tendency nor decreased physical function; D or Low-P group, with a depressive tendency or decreased physical function; D and Low-P group, with depressive tendency and decreased physical function. KaplanMeier survival analysis, Bonferroni's multiple comparison test, and Cox proportional hazards analysis were used. The dependent variables were all-cause mortality and readmission for heart failure, and the dependent variables were HADS and physical function. In multivariate analysis, all-cause mortality was adjusted by age, BMI, and BNP, and readmission due to heart failure was adjusted by age, sex, BMI, BNP, Alb and the presence or absence of chronic heart failure. JMP (ver. 13.1) was used for statistical analysis. In all analyses, $P<0.05$ was taken to indicate statistical significance.

\section{Results}

\section{Study population}

The baseline characteristics for all patients and for groups classified according to HADS are shown in Table 1. The study population had a median age of 72 (67-78) years, consisted of $70.8 \%$ males, and had a median HADS of 4 (2-7). Among 472 patients, 109 (23.1\%) were positive for depressive tendency according to HADS. CVD patients with depressive tendencies had significantly higher rates of chronic heart failure and higher circulating BNP levels than non-depressive patients.

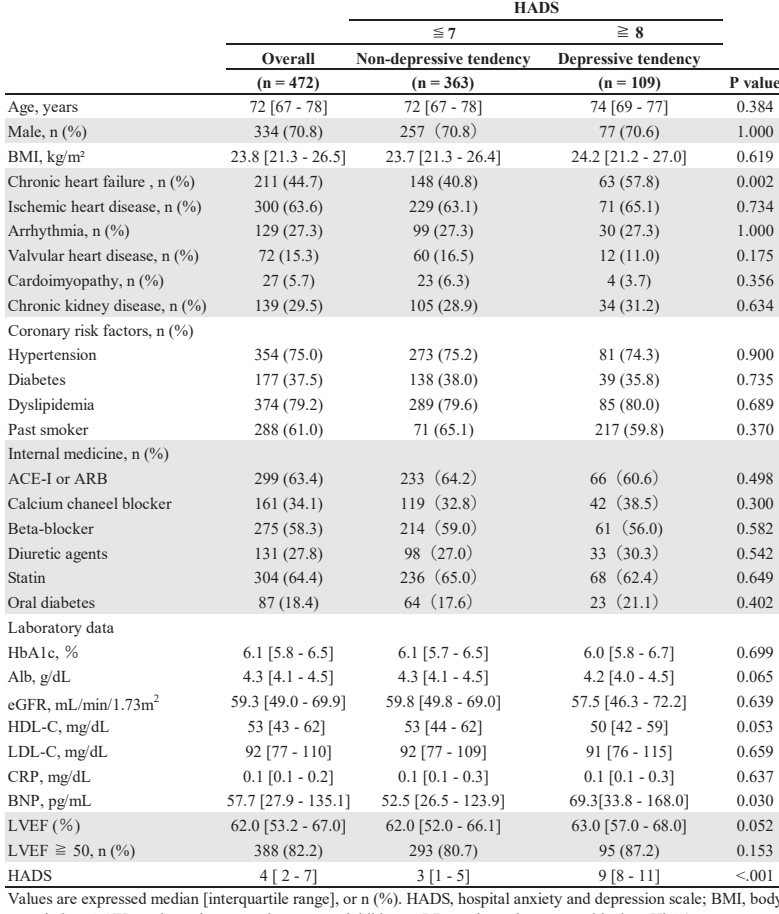

mass index; ACEI, angiotensin-converting enzyme inhibitor; ARB, angiotensin-receptor blocker; $\mathrm{HbAlc}$,

HemoglobinA Ac; Alb, Albumin; eGFR, estimated glomerular filtration rate; HDL-C, high-density lipoprotein

cholesterol; LDL-C, low-density lipoprotein cholesterol; CRP, C-reactive protein; BNP, B-type natriuretic peptide;

LVEF, left ventricular ejection fraction

\section{Relationship between depressive tendency and physical function}

Table 2 presents the results of multivariate linear regression analyses for predicting physical function. HADS was an independent determinant of physical function index in all models. In particular, gait speed and 6MWD with the high absolute value of the standardized regression coefficient were more closely related to depressive tendency. Next, the results of the comparison of physical function by covariance analysis, classified according to the presence or absence of depressive tendency, are shown in Figure 1. Patients with CVD and depressive tendencies showed significantly lower values of all parameters of physical function.

Relationships between prognosis, depressive tendency, and physical function: The median observation periods were 46 (27-78) months for all-cause mortality and 43.5 (25-72) months for readmission due to heart failure until the end of the observation period at 84 months. The total numbers of events were 32 all-cause mortalities and 50 readmissions due to heart failure. Kaplan-Meier survival curves are shown in Figures 2 and 3. The rate of all-cause mortality was significantly higher in the D and Low-P group than in groups Non-D and High-P and $\mathrm{D}$ or Low-P in 6MWD. The rate of readmission due to heart failure was significantly higher in groups D or Low-P and D and Low-P than group Non-D and High-P in grip strength, QIS, and gait speed. 6MWD showed differences between all groups.

Tables 3 and 4 show the results of univariate and multivariate Cox proportional hazard analyses. In multivariate analysis, all-cause mortality was adjusted by age, BMI and 


\begin{tabular}{|c|c|c|c|c|c|c|c|c|c|c|c|c|}
\hline \multirow[b]{2}{*}{ Physical function } & \multicolumn{4}{|c|}{ Model 1} & \multicolumn{4}{|c|}{ Model 2} & \multicolumn{4}{|l|}{ Model3 } \\
\hline & B & $95 \% \mathrm{CI}$ & $\beta$ & $P$ value & B & $95 \% \mathrm{CI}$ & $\beta$ & $P$ value & B & $95 \% \mathrm{CI}$ & $\beta$ & $P$ value \\
\hline Grip strength & -0.23 & $-0.40--0.06$ & -0.09 & 0.009 & -0.19 & $-0.36--0.01$ & -0.07 & 0.036 & -0.19 & $-0.37--0.02$ & -0.07 & 0.029 \\
\hline QIS & -0.59 & $-0.89--0.29$ & -0.15 & $<0.001$ & -0.59 & $-0.89--0.28$ & -0.15 & $<0.001$ & -0.61 & $-0.92--0.30$ & -0.16 & $<0.001$ \\
\hline Gait speed & -0.02 & $-0.02--0.01$ & -0.21 & $<0.001$ & -0.01 & $-0.02--0.01$ & -0.18 & $<0.001$ & -0.01 & $-0.02--0.01$ & -0.19 & $<0.001$ \\
\hline $6 \mathrm{MWD}$ & -6.62 & $-8.94--4.30$ & -0.21 & $<0.001$ & -5.44 & $-7.70--3.18$ & -0.17 & $<0.001$ & -5.44 & $-7.71--3.18$ & -0.17 & $<0.001$ \\
\hline
\end{tabular}

Model 1: adjusted for age, gender, body mass index (BMI), hospital anxiety and depression scale (HADS). Model 2: adjusted for model $1+$

HemoglobinA1c (HbAlc), Albumin (Alb), estimated glomerular filtration rate (eGFR), C-reactive protein (CRP), B-type natriuretic peptide (BNP), left ventricular ejection fraction (LVEF), the presence or absence of chronic heart failure. Model 3: adjusted for model $2+$ the presence or absence of hypertension, dyslipidemia, diabetes, and smoking, which are coronary risk factors.

$\mathrm{B}$, regression coeffidencent; CI, confidence interval; $\beta$, standardized regression coefficient; QIS, quadriceps isometric strength; 6MWD, 6-minute walking distance.
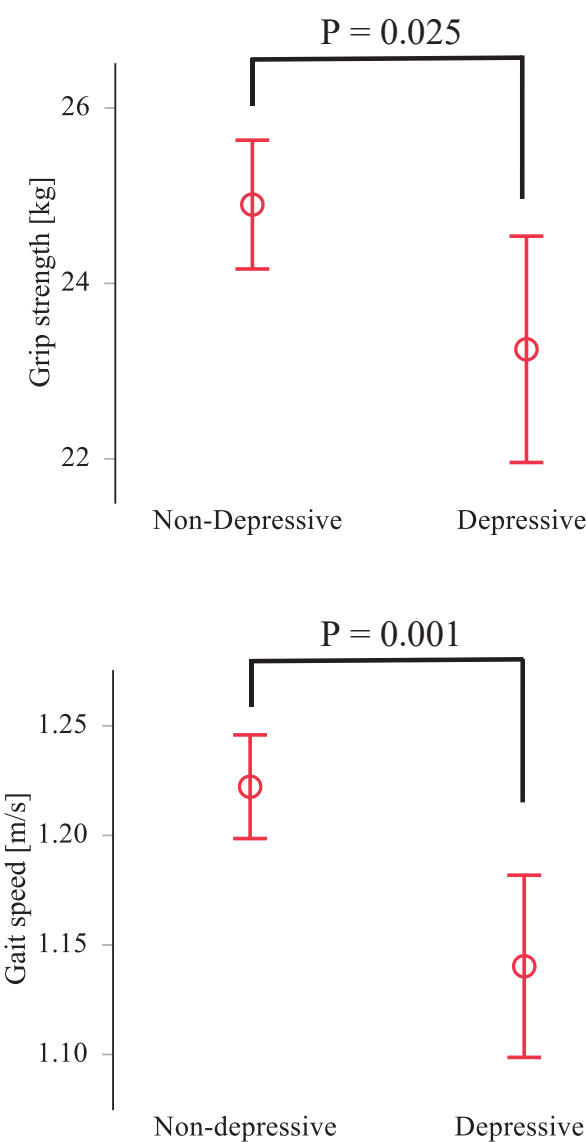

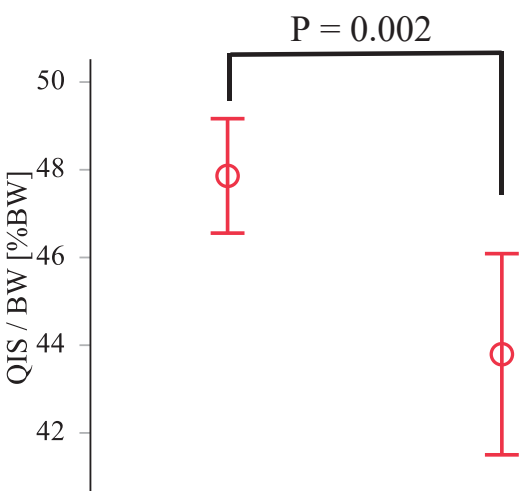

Non-depressive Depressive

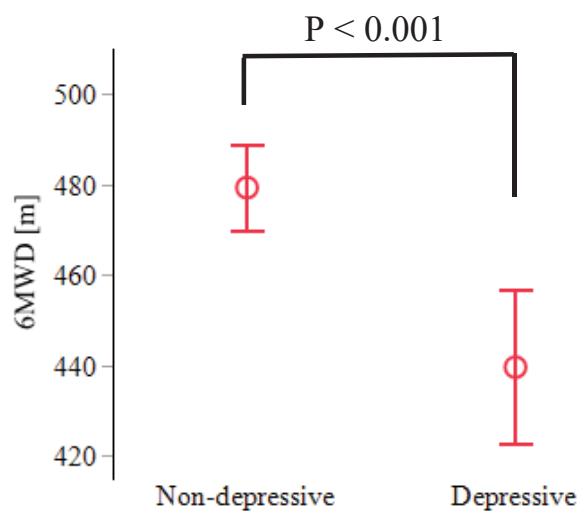

Figure 1: Relationship between depressive tendency and physical function.

Comparison of physical function between the depressive group and non-depressive group by analysis of covariance (ANCOVA) adjusted for age, gender, BMI, HbA1C Alb, eGFR, CRP, BNP, LVEF and the presence or absence of chronic heart failure as covariates. Red dots indicate adjusted mean values, with error bars representing $95 \%$ confidence intervals. QIS, quadriceps isometric strength; BW, body weight; 6MWD, 6-minute walking distance.

BNP, and readmission due to heart failure was adjusted by age, sex, BMI, BNP,

Alb and the presence or absence of chronic heart failure. In univariate and multivariate analysis, the $\mathrm{D}$ and Low-P group had a higher risk of all-cause mortality than group Non-D and High-P in 6MWD. Also, the risk of readmission due to heart failure was higher in groups D and Low-P and D or Low-P than group Non-D and High-P in all physical functions.

\section{Discussion \& conclusion}

In this study, the proportion of patients with depressive tendencies as determined by HADS was $23.1 \%$. The proportions of patients with chronic heart failure and circulating levels of BNP were significantly higher in the group of CVD patients with depressive tendencies than in the non-depressive tendency group. HADS is an independent determinant of physical function taking into consideration confounding factors, and the 
Grip strength

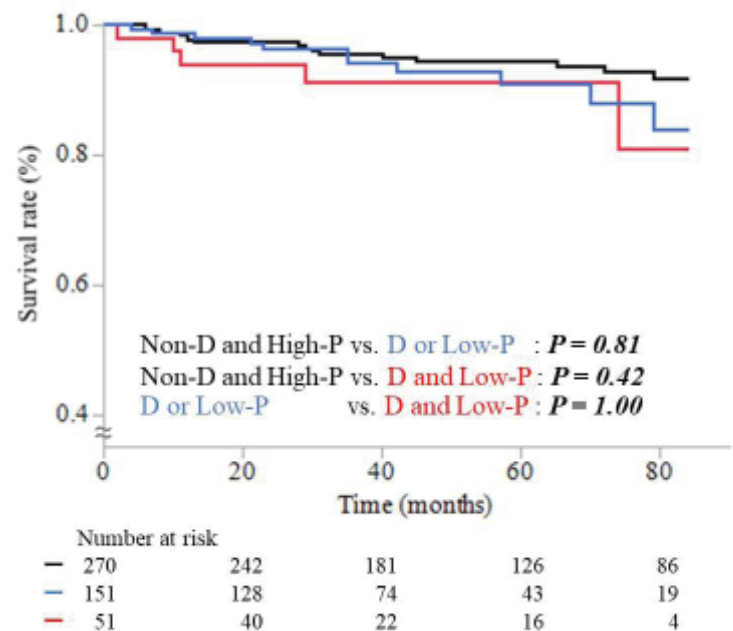

Gait speed

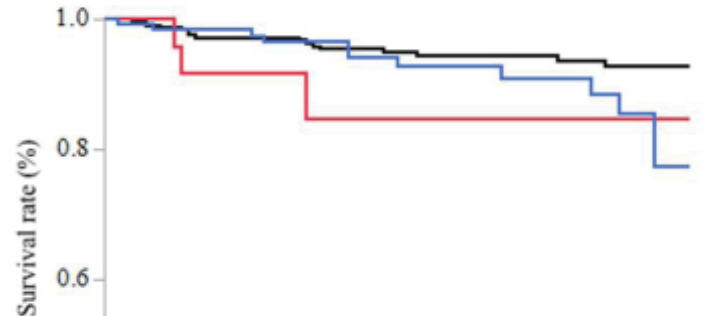

Non-D and High-P vs. D or Low-P : $\boldsymbol{P}=0.21$

Non-D and High-P vs. D and Low-P: $\boldsymbol{P}=\mathbf{0 . 2 0}$

$0.4-D$ or Low-P vs. D and Low-P : $\boldsymbol{P}=\boldsymbol{0 . 8 0}$

గึ

20

20

40

Time (months)

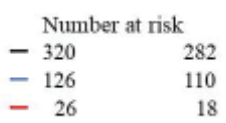

200

70

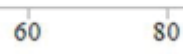

80

133
47

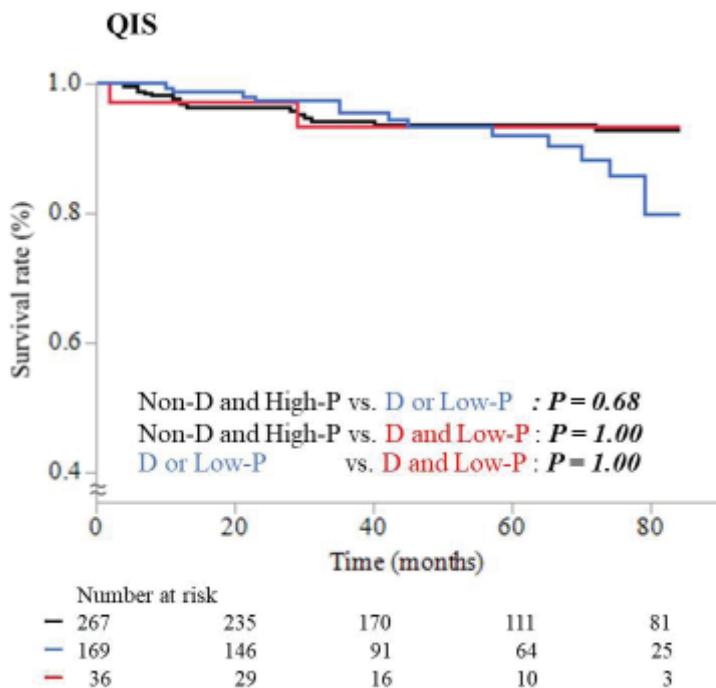

6MWD

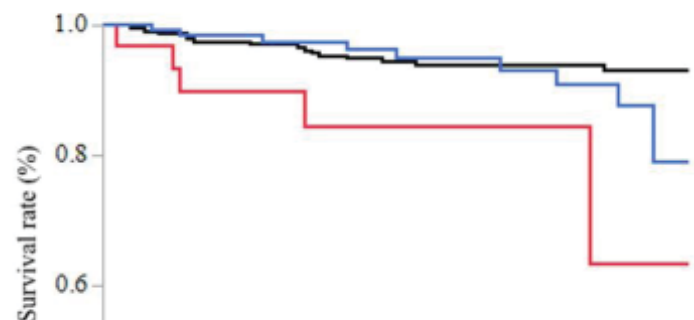

Non-D and High-P vs. D or Low-P : $\boldsymbol{P}=\mathbf{0 . 7 8}$

Non-D and High-P vs. D and Low-P: $P=<0.05$

0.4 D or Low-P vs. D and Low-P : $\boldsymbol{P}=<\boldsymbol{0 . 0 5}$

\begin{tabular}{|c|c|c|c|c|}
\hline 0 & 20 & 40 & 60 & 80 \\
\hline
\end{tabular}

\begin{tabular}{rrrrr}
\multicolumn{2}{c}{ Number at risk } & & & \\
-310 & 275 & 197 & 131 & 92 \\
-130 & 114 & 74 & 49 & 16 \\
$-\quad 32$ & 21 & 6 & 5 & 1
\end{tabular}

Figure 2: Kaplan-Meier analysis of all-cause mortality according to depressive tendency and physical function.

Kaplan-Meier survival analysis of all-cause mortality in patients classified into three groups according to presence or absence of depressive tendency and/or decreased physical function: Non-D and High-P group, with neither depressive tendency nor decreased physical function; D or Low-P group, depressive tendency or decreased physical function; and D and Low-P group, depressive tendency and decreased physical function. The black line represents Non-D and High-P group, the blue line represents D or Low-P group, and the red line represents D and Low-P group. QIS, quadriceps isometric strength; 6MWD, 6-minute walking distance.

depressive tendency group showed significantly lower values in all measures of physical function than the non-depressive tendency group. The combinations of depressive tendency and only decreased 6MWD group significantly increased the incidences of all-cause mortality and readmission due to heart failure compared to the D or Low-P group and the Non-D and High-P group. In Cox proportional hazards analysis, the combination of depressive tendency and decreased 6MWD further increased the risks of all-cause mortality and readmission due to heart failure. In patients with CVD, the depressive tendency was associated with decreased physical function, and their combination was associated with poor prognosis. The prevalence of depression in CVD patients has been reported to be $17.5 \%$ to $46.3 \%$ [1-3]. The population in this study did not consist of acute CVD patients, but in outpatients with chronic CVD. The prevalence of depression in the present study was $23.1 \%$, which was consistent with previous reports.
The combination of depression with CVD and in communitydwelling elderly people has been reported to be poor prognostic factors [7,11]. In addition, it has been reported that among community-dwelling elderly people, the depressive tendency is associated with chronic inflammation [27] and decreased physical activity [14], possibly resulting in decreased physical function. However, the relationship between depressive tendency and physical function in patients with CVD and the effects of the combination of both on prognosis is not clear. To our knowledge, this is the first report regarding the relationship between depressive tendency and physical function in patients with CVD and the effects of their combination on prognosis.

The depressive tendency is caused by chest pain [1] fatigue [3] and autonomic abnormalities [28] due to decreased cardiac function. On the other hand, the cardiac function has been reported to decline as a result of decreased heart rate variability 

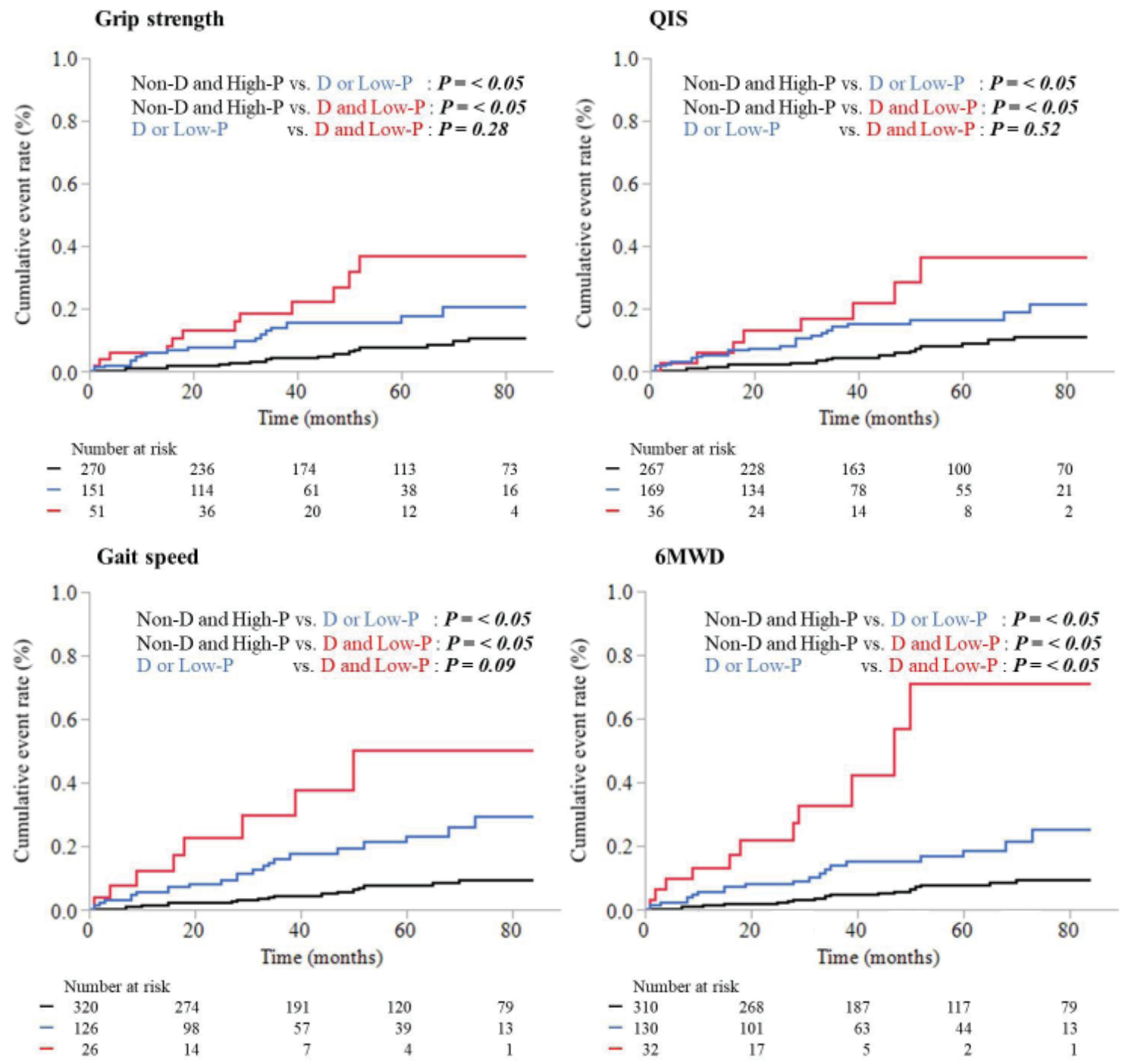

Figure 3: Kaplan-Meier analysis of readmission due to heart failure according to depressive tendency and physical function

Kaplan-Meier survival analysis of readmission due to heart failure in patients classified into three groups according to presence or absence of depressive tendency and/ or decreased physical function: Non-D and High-P group, with neither depressive tendency nor decreased physical function; D or Low-P group, depressive tendency or decreased physical function; and D and Low-P group, depressive tendency and decreased physical function. The black line represents Non-D and High-P group, the blue line represents D or Low-P group, and the red line represents D and Low-P group. QIS, quadriceps isometric strength; 6MWD, 6-minute walking distance.

due to depression [29]. Therefore, the study concluded that CVD patients with depressive tendencies due to these causes may have significantly higher rates of chronic heart failure and higher circulating BNP levels than non-depressive patients. However, there were no significant differences in LVEF associated with depressive tendencies. The number of heart failure patients without systolic dysfunction is increasing [30]. This may be due to appropriate disease management in patients with chronic CVD. LVEF was normal in both groups in this study, so there was no significant difference between patients with and without depressive tendencies. It has also been reported that ischemic heart disease [31] and arrhythmia [32] are involved in the development of depression, but there were no significant differences in the percentages of patients with ischemic heart disease and arrhythmia between the two groups in this study.

Various mechanisms have been proposed for the relationship between depressive tendency and physical function in patients with CVD, but the underlying mechanism is still unknown. Patients with CVD develop heart failure symptoms at a high rate, leading to decreased peripheral blood flow, chronic inflammation [27], decreased physical activity [33] and malnutrition [34], which may cause skeletal muscle disorder and decreased physical function [35]. On the other hand, decreased physical function may increase the incidence of cardiovascular events due to decreased balance ability [36] and vascular endothelial Dysfunction [37]. In this study, the depressive tendency determined by HADS was considered to be an independent determinant of physical function, suggesting that physical function declines due to the combination with depressive tendency. However, the subjects of this study are patients with chronic cardiovascular disease who regularly cooperate with doctors, nurses, and physiotherapists to manage the disease as secondary prevention. Therefore, since the state was relatively stable, it is considered that there was no 


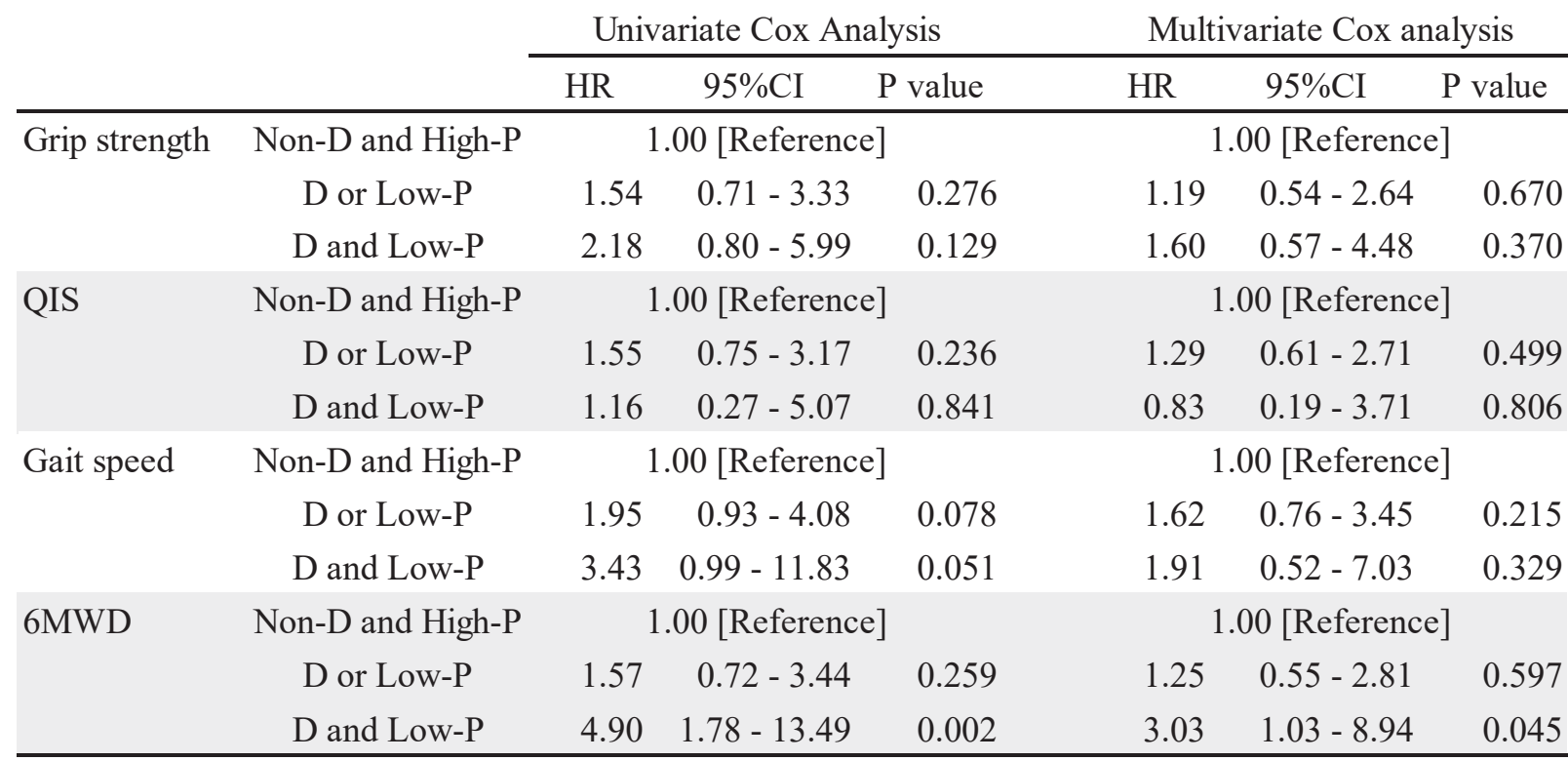

HR: hazard ratio; CI: confidence interval; QIS: quadriceps isometric strength; 6MWD: 6-minute walking distance; Non-D and High-P: the group without depressive tendency and decreased physical function; D or Low-P: the group with depressive tendency or decreased physical function; D and Low-P: the group with depressive tendency and decreased physical function

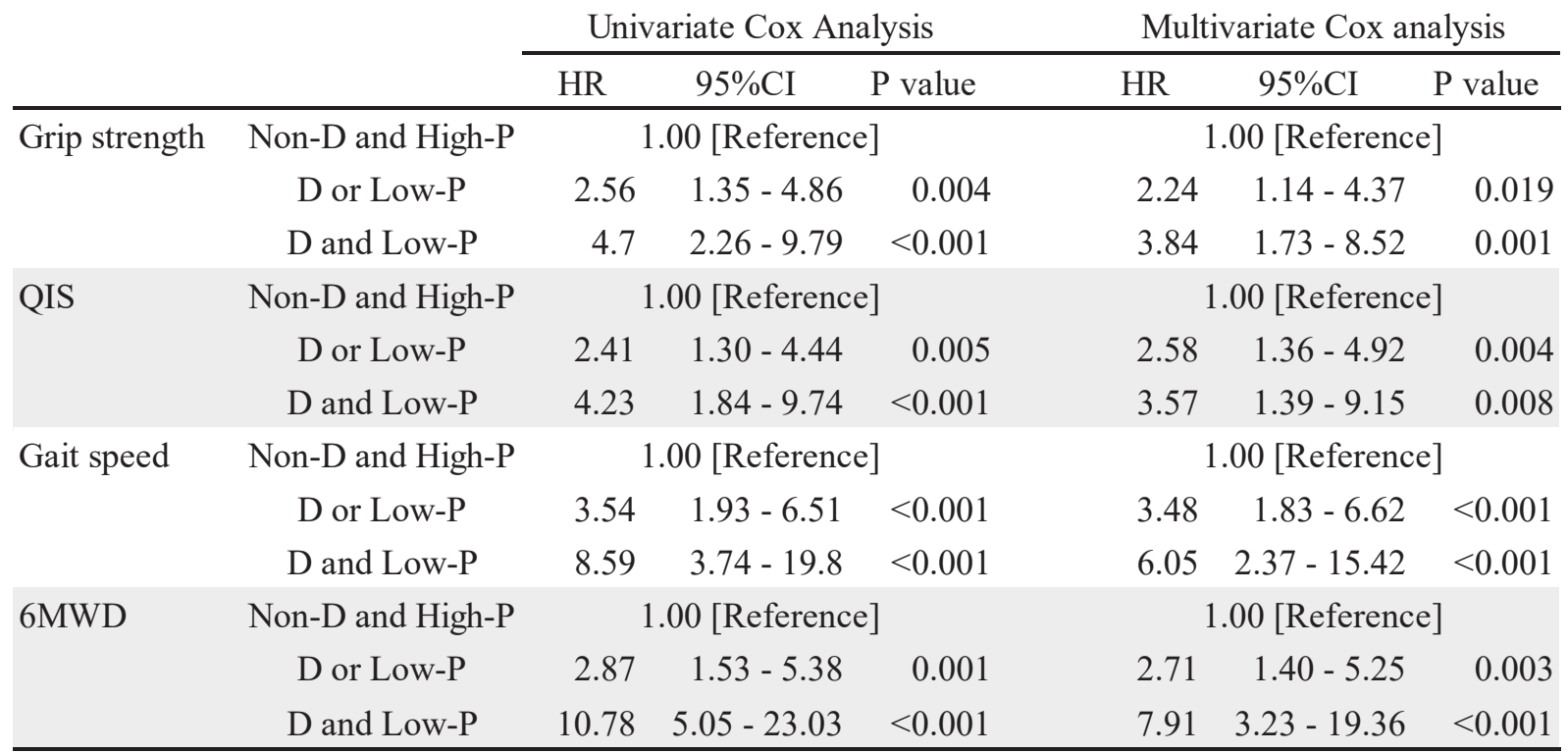

HR: hazard ratio; CI: confidence interval; QIS: quadriceps isometric strength; 6MWD: 6-minute walking distance; Non-D and High-P: the group without depressive tendency and decreased physical function; D or Low-P: the group with depressive tendency or decreased physical function; D and Low-P: the group with depressive tendency and decreased physical function

significant difference in the reference values for the various data such as CRP and Alb. CVD patients with depressive tendencies have been reported to show vascular endothelial dysfunction $[38,39]$ platelet dysfunction [40], left ventricular dysfunction
[41-42] reduced adherence to disease management [43] and increased prevalence of lifestyle-related diseases [44], all of which result in poor prognosis. Also, the coronary risk factors, diabetes [45] and smoking [46] and the use of antidepressants 
[46] and beta-blockers [47] have been reported to be associated with depression. However, the rates of these factors and HbA1c, HDL-C, or LDL-C, which are biomarkers of diabetes and dyslipidemia were not significantly different between the two groups in this study. Patients who have been diagnosed with mental illness were excluded from this study, so the cohort did not include patients using antidepressants.

Therefore, the factors in this study that showed lower values in all measures of physical function in the depressive tendency group compared with the non-depressive tendency group are likely due to a decrease in physical activity and vascular endothelial damage due to the depressive tendency. In recent years, there have been many reports that vascular endothelial function and physical activity are related to physical function.

There are several determinants of $6 \mathrm{MWD}$, including cardiopulmonary function, skeletal muscle mass and strength, and mitochondrial function [48]. 6MWD is considered to be a comprehensive measure of physical function that incorporates the elements of grip strength as an index of arm strength QIS as an index of lower limb strength, and gait speed as a measure of movement ability measured in the present study. 6MWD is considered to be an indicator of muscle strength and cardiopulmonary function, as well as an indicator of functional ability in activities of daily living [49]. It has been reported that $6 \mathrm{MWD}$, which is an indicator of exercise tolerant and comprehensive physical function, is closely related to decreased physical activity and malnutrition, and may further decrease exercise tolerability. It has been reported that depressive tendency causes social isolation and decreased physical activity. In this study, a combination of depressive tendencies and decreased 6MWD triggered a vicious cycle, which may be associated with decreased physical activity, malnutrition, and decreased cardiac function. These factors may be associated with poor prognosis for both all-cause mortality and readmission due to heart failure.

This study had several limitations. First, this study was performed in a single center. Second, the study population consisted only of Japanese patients with CVD, and there were few deaths in the cohort during the observation period. Moreover, many patients were excluded from the analysis as they could not complete baseline physical function and HADS.

In conclusion, the depressive tendency is associated with decreased physical function, and their combination is associated with poor prognosis in patients with CVD.

\section{Acknowledgments}

We thank all the staff members of the Kitasato University who collaborated in this study.

\section{Funding}

This work was supported by MEXT KAKENHI (Grants-inaid for Scientific Research from the Ministry of Education, Culture, Sports, Science and Technology)

\section{References}

1. Mayou RA, Gill D, Thompson DR, Day A, Hicks N, et al. (2000) Depression and anxiety as predictors of outcome after myocardial infarction. Psychosom Med 62: 212-219. Link: https://bit.ly/3alz4D1

2. Shiotani I, Sato H, Kinjo K, Nakatani D, Mizuno H, et al. (2002) Depressive symptoms predict 12-month prognosis in elderly patients with acute myocardial infarction. J Cardiovasc Risk 9: 153-160. Link: https://bit.ly/2yrHcEU

3. Cheok F, Schrader G, Banham D, Marker J, Hordacre AL (2003) Identification course, and treatment of depression after admission for a cardiac condition: rationale and patient characteristics for the Identifying Depression As a Comorbid Condition (IDACC) project. Am Heart J 146: 978-984. Link: https://bit.ly/2yunmbQ

4. Lichtman JH, Bigger JT, Blumenthal JA (2008) Depression and coronary heart disease: recommendations for screening, referral, and treatment: a science advisory from the American Heart Association Prevention Committee of the Council on Cardiovascular Nursing, Council on Clinical Cardiology, Council on Epidemiology and Prevention, and Interdisciplinary Council on Quality of Care and Outcomes Research: endorsed by the American Psychiatric Association. Circulation 118: 1768-1775. Link: https://bit.ly/2RQY4f2

5. World Health Organization (2020) The Global Burden of Disease 2004 Update. Link: https://bit.ly/2xHU5dR

6. Anda R, Williamson D, Jones D (1993) Depressed affect, hopelessness, and the risk of ischemic heart disease in a cohort of U.S. adults. Epidemiology 4 285-294. Link: https://bit.ly/3blmwNq

7. Meijer A, Conradi HJ, Bos EH, Thombs BD, van Melle JP, et al. (2011) Prognostic association of depression following myocardial infarction with mortality and cardiovascular events: a meta-analysis of 25 years of research. Gen Hosp Psychiatry 33: 203-216. Link: https://bit.ly/2KjfOGN

8. Xu SD, Su GH, Lu YX (2014) Elevated soluble ST2 and depression increased the risk of all-cause mortality and hospitalization in patients with heart failure. Int Heart J 55: 445-450. Link: https://bit.ly/3bixpPX

9. Lesperance F, Frasure-Smith N, Talajic M, Bourassa MG (2002) Five-year risk of cardiac mortality in relation to initial severity and one-year changes in depression symptoms after myocardial infarction. Circulation 105: 1049 1053. Link: https://bit.ly/3cugyK8

10. Li H, Van Halm-Lutterodt N, Zheng D (2018) Time-dependent depressive symptoms and risk of cardiovascular and all-cause mortality among the Chinese elderly: The Beijing Longitudinal Study of Aging. J Cardiol 72: 356 362. Link: https://bit.ly/34R1V16

11. Penninx BW, Beekman AT, Honig A (2001) Depression and cardiac mortality: results from a community-based longitudinal study. Arch Gen Psychiatry 58 221-227. Link: https://bit.ly/3ezDJV7

12. Ferketich AK, Schwartzbaum JA, Frid DJ, Moeschberger ML (2000) Depression as an antecedent to heart disease among women and men in the NHANES study. National Health and Nutrition Examination Survey. Arch Intern Med 160 1261-1268. Link: https://bit.ly/2RT80Vh

13. Volaklis K, Mamadjanov T, Meisinger C, Linseisen J (2019) Association between muscular strength and depressive symptoms : A narrative review. Wien Klin Wochenschr 131: 255-264. Link: https://bit.ly/2wREKaa

14. Patten SB, Williams JVA, Lavorato DH, Eliasziw M (2009) A longitudinal community study of major depression and physical activity. General Hospital Psychiatry 31: 571-575. Link: https://bit.ly/2VHatmL

15. Kamiya K, Hamazaki N, Matsue Y (2018) Gait speed has comparable prognostic capability to six-minute walk distance in older patients with cardiovascular disease. Eur J Prev Cardiol 25: 212-219. Link: https://bit.ly/3aoKwh6

16. Kamiya K, Masuda T, Tanaka S (2015) Quadriceps Strength as a Predictor of Mortality in Coronary Artery Disease. Am J Med 128: 1212-1219. Link: https://bit.ly/3cxuNON

Citation: Osada K, Yamaoka-Tojo M, Obara S, Kariya H, Kato Y, et al. (2020) A combination of depression and decreased physical function further worsens the prognosis of patients with chronic cardiovascular disease. J Cardiovasc Med Cardiol 7(2): 063-071. D0I: https://dx.doi.org/10.17352/2455-2976.000115 
17. Newman AB, Kupelian V, Visser M, Simonsick EM, Goodpaster BH, et al. (2006) Strength, but not muscle mass, is associated with mortality in the health, aging and body composition study cohort. J Gerontol A Biol Sci Med Sci 61: 72-77. Link: https://bit.ly/34WqrxO

18. Zigmond AS, Snaith RP (1983) The hospital anxiety and depression scale. Acta Psychiatr Scand 67: 361-370. Link: https://bit.ly/3bmPTyV

19. Kitamura T (1993) Hospital anxiety and depression scale (HADS). Archives of psychiatric diagnostics and clinical evaluation (Japanese) 4: 371-372.

20. Ando Y, Ito S, Uemura O (2009) CKD Clinical Practice Guidebook. The essence of treatment for CKD patients. Clin Exp Nephrol 13: 191-248. Link: https://bit.ly/2wVs9ms

21. ATS statement (2002) Guidelines for the six-minute walk test. Am J Respir Crit Care Med 166: 111-117.

22. Chen LK, Liu LK, Woo J (2014) Sarcopenia in Asia: consensus report of the Asian Working Group for Sarcopenia. J Am Med Dir Assoc 15: 95-101. Link: https://bit.ly/2VDjsWa

23. Azegami M, Ohira M, Miyoshi K (2007) Effect of single and multi-joint lowe extremity muscle strength on the functional capacity and ADL/IADL status in Japanese community-dwelling older adults. Nurs Health Sci 9: 168-176. Link: https://bit.ly/2xzEm0B

24. Cesari M, Kritchevsky SB, Penninx BW (2005) Prognostic value of usua gait speed in well-functioning older people--results from the Health, Aging and Body Composition Study. J Am Geriatr Soc 53: 1675-1680. Link: https://bit.ly/2RR0p90

25. Morley JE, Abbatecola AM, Argiles JM (2011) Sarcopenia with limited mobility: An international consensus. J Am Med Dir Assoc 12: 403-409. Link: https://bit.ly/2KhFjgB

26. Brennan C, Worrall-Davies A, McMillan D, Gilbody S, House A (2010) The Hospital Anxiety and Depression Scale: A diagnostic meta-analysis of case-finding ability. Journal of Psychosomatic Research 69: 371-378. Link: https://bit.ly/2xGCYZO

27. Miller GE, Stetler CA, Carney RM, Freedland KE, Banks WA (2002) Clinical depression and inflammatory risk markers for coronary heart disease. Am J Cardiol 90: 1279-1283. Link: https://bit.ly/2VoLPbU

28. Krittayaphong R, Cascio WE, Light KC (1997) Heart rate variability in patients with coronary artery disease: differences in patients with higher and lower depression scores. Psychosom Med 59: 231-235. Link: https://bit.ly/34PegT9

29. Gorman JM, Sloan RP (2000) Heart rate variability in depressive and anxiety disorders. Am Heart J 140: 77-83. Link: https://bit.ly/2KkKhck

30. Owan TE, Hodge DO, Herges RM, Jacobsen SJ, Roger VL, et al. (2006) Trends in prevalence and outcome of heart failure with preserved ejection fraction. $\mathrm{N}$ Engl J Med 355: 251-259. Link: https://bit.ly/2VluQQz

31. Shimizu Y, Suzuki M, Okumura H, Yamada S (2014) Risk factors for onse of depression after heart failure hospitalization. J Cardiol 64: 37-42. Link: https://bit.ly/2KikCkz

32. Suzuki T, Shiga T, Kuwahara K (2014) Impact of clustered depression and anxiety on mortality and rehospitalization in patients with heart failure. $J$ Cardiol 64: 456-462. Link: https://bit.ly/2ysJHGS

33. He J, Ogden LG, Bazzano LA, Vupputuri S, Loria C, et al. (2001) Risk factors for congestive heart failure in US men and women: NHANES I epidemiologic follow-up study. Arch Intern Med 161: 996-1002. Link: https://bit.ly/2ysJIKW

34. Matsuo H, Yoshimura Y, Fujita S, Maeno $Y$ (2019) Risk of malnutrition is associated with poor physical function in patients undergoing cardiac rehabilitation following heart failure. Nutr Diet 76: 82-88. Link: https://bit.ly/3aopvmW

35. Harrington D, Anker SD, Chua TP (1997) Skeletal muscle function and its relation to exercise tolerance in chronic heart failure. J Am Coll Cardiol 30 1758-1764. Link: https://bit.ly/2KjSkq8

36. Nofuji Y, Shinkai S, Taniguchi Y (2016) Associations of Walking Speed, Grip Strength, and Standing Balance With Total and Cause-Specific Mortality in a General Population of Japanese Elders. J Am Med Dir Assoc 17: 184.e1-7. Link: https://bit.ly/3aj8D0V

37. Yoo JI, Kim MJ, Na JB (2018) Relationship between endothelial function and skeletal muscle strength in community dwelling elderly women. J Cachexia Sarcopenia Muscle 9: 1034-1041. Link: https://bit.ly/3exNoeV

38. Sherwood A, Hinderliter AL, Watkins LL, Waugh RA, Blumenthal JA (2005) Impaired endothelial function in coronary heart disease patients with depressive symptomatology. J Am Coll Cardiol 46: 656-659. Link: https://bit.ly/3atebGh

39. Pizzi C, Manzoli L, Mancini S, Costa GM (2008) Analysis of potential predictors of depression among coronary heart disease risk factors including heart rate variability, markers of inflammation, and endothelial function. Eur Heart J 29 : 1110-1117. Link: https://bit.ly/2wRhHME

40. Laghrissi-Thode F, Wagner WR, Pollock BG, Johnson PC, Finkel MS (1997) Elevated platelet factor 4 and beta-thromboglobulin plasma levels in depressed patients with ischemic heart disease. Biol Psychiatry 42: 290-295. Link: https://bit.ly/2yvPVFP

41. Takemura Y, Kikuchi S, Takagi H, Inaba Y, Nakagawa K (1998) A cross sectional study on the relationship between depression and left ventricular hypertrophy. Prev Med 27: 787-791. Link: https://bit.ly/2VpyrEp

42. van Melle JP, de Jonge P, Ormel J (2005) Relationship between left ventricula dysfunction and depression following myocardial infarction: data from the MIND-IT. Eur Heart J 26: 2650-2656. Link: https://bit.ly/3eAc2LU

43. DiMatteo MR, Lepper HS, Croghan TW (2000) Depression is a risk factor for noncompliance with medical treatment: meta-analysis of the effects of anxiety and depression on patient adherence. Arch Intern Med 160: 2101-2107. Link: https://bit.ly/3bzlpKd

44. Rosal MC, Ockene JK, Ma Y (2001) Behavioral risk factors among members of a health maintenance organization. Prev Med 33: 586-594. Link: https://bit.ly/2Kouf13

45. Nouwen A, Adriaanse MC, van Dam K (2019) Longitudinal associations between depression and diabetes complications: a systematic review and meta-analysis. Diabet Med 36: 1562-1572. Link: https://bit.ly/2XOuMkZ

46. Caro MA, Sowden GL, Mastromauro CA (2012) Risk factors for positive depression screens in hospitalized cardiac patients. J Cardiol 60: 72-77. Link: https://bit.ly/2RTajYr

47. Kato N, Kinugawa K, Shiga T (2012) Depressive symptoms are common and associated with adverse clinical outcomes in heart failure with reduced and preserved ejection fraction. J Cardiol 60: 23-30. Link: https://bit.ly/3eA4Glu

48. Okita K, Kinugawa S, Tsutsui H (2013) Exercise intolerance in chronic heart failure--skeletal muscle dysfunction and potential therapies. Circ J 77: 293 300. Link: https://bit.ly/2VNMOwq

49. Holland AE, Spruit MA, Troosters T (2014) An official European Respiratory Society/American Thoracic Society technical standard: field walking tests in chronic respiratory disease. Eur Respir J 44: 1428-1446. Link: https://bit. ly/3cxxG1D

Copyright: ( 2020 Osada K, et al. This is an open-access article distributed under the terms of the Creative Commons Attribution License, which permits unrestricted use, distribution, and reproduction in any medium, provided the original author and source are credited.

Citation: Osada K, Yamaoka-Tojo M, Obara S, Kariya H, Kato Y, et al. (2020) A combination of depression and decreased physical function further worsens the prognosis of patients with chronic cardiovascular disease. J Cardiovasc Med Cardiol 7(2): 063-071. DOI: https://dx.doi.org/10.17352/2455-2976.000115 